\title{
Benefits of dual chamber pacing in sick sinus syndrome
}

TAKAO MITSUOKA, ROSE ANNE KENNY, TONY AU YEUNG, SIEW LU CHAN, के JOHN E PERRINS, RICHARD SUTTON

From the Department of Cardiology, Westminster Hospital, London

SUMMARY The effects of DDD (fully automatic) and VVI (ventricular demand) pacing modes of exercise tolerance, symptom diary cards, and Holter monitoring were investigated in a randomise double blind crossover study of 16 patients who had had DDD pacemakers implanted because of frequent syncope. Eight patients presented with sick sinus syndrome and, with one exceptioep, retrograde atrioventricular conduction and eight age and sex matched patients presented with 2.3 or complete atrioventricular block. Maximal symptom limited exercise in those with atrioventricular block was significantly higher after one month of DDD pacing than after VVI pacing. those with sick sinus syndrome, however, maximal effort tolerance was not significantly different for the two pacing modes. In all but one patient with sick sinus syndrome sinus rhythm developed during exercise in VVI pacing. For both VVI and DDD modes maximal atrial rates we significantly lower in those with sick sinus syndrome. Palpitation and general wellbeing wefe significantly improved during DDD pacing in the eight patients with sick sinus syndromg. Shortness of breath was improved by DDD pacing in the eight patients with atrioventricular block but not in those with sick sinus syndrome. Holter monitoring showed that sick sinus syndronge patients remained in paced rhythm, either DDD or VVI, for most of the 24 hour period.

DDD pacing was better than VVI pacing in sick sinus syndrome with retrograde atrioventricular conduction. Despite their ability to show sinus rhythm and inhibit their pacemakers on exercise patients with sick sinus syndrome are just as likely to have symptomatic benefit from DDD pacing as patients with atrioventricular block.

The availability of a reliable endocardial atrial lead ${ }^{1-3}$ led to the development of "physiological" pacemakers that restore the normal activation sequence of atrial contraction followed by ventricular systole and that also permit a physiological increase in heart rate when the sinus rate increases.

Atrial demand pacemakers (AAI) were introduced as a physiological system for patients with sick sinus syndrome. They offered the same advantages as DDD (fully automatic) pacemakers but could not pace the ventricle if a fault developed in atrioventricular conduction. Subsequent development of atrioventricular block, carotid sinus hypersensitivity, and chronic atrial fibrillation made many of these patients unsuitable candidates for AAI pac-

Requests for reprints to Dr Richard Sutton, Westminster Hospital, Dean Ryle Street, London SW1P 2AP.

Accepted for publication 19 January 1988 ing ${ }^{5}$; however, not every study reported this problem. ${ }^{67}$ A recent review of the course of sick sinus syndrome suggests that those concerns are reas: Atrial synchronous ventricular pacing (VAT, VDB) was unsuitable for patients with sick sinus syndrorge because of the potential for persistent bradycardia which causes these units to pace in VVI mode at low rate. An atrioventricular sequential pacemaker (DVI) can be used for patients with sick sinus syndrome; however, Furman and Cooper' reportecta high incidence of atrial fibrillation with DVI pacing, possibly because of competition with atrial activify which is not sensed in this mode. Thus DDD appetss to be an appropriate semi-physiological pacing moge for patients with sick sinus syndrome. This type of unit does not correct for the lack of ability of the sinus node to increase its rate normally on exercise. 7 future generation of DDD pacemakers will have in additional physiological sensor (other than the $\$$ wave) to offer this correction. 
Retrograde atrioventricular conduction is preserved in most patients with sick sinus syndrome who have intact atrioventricular conduction. ${ }^{1011}$ Pacemaker syndrome develops when atrioventricular synchrony is lost during VVI (ventricular demand) pacing with or without retrograde atrioventricular conduction. ${ }^{12} 13$ Recent studies have emphasised the relation between preserved retrograde atrioventricular conduction and the development of pacemaker syndrome. ${ }^{14}$ Because of preservation of retrograde atrioventricular conduction, patients with sick sinus syndrome and without atrioventricular block potentially are at more risk of pacemaker syndrome if paced in the VVI mode than patients with intermittent or complete anterograde atrioventricular block, in which retrograde atrioventricular conduction is also compromised. Despite this, VVI pacing has been frequently used for sick sinus syndrome patients.

This is the first study to compare (a) exercise tolerance and symptoms in DDD and VVI modes in sick sinus syndrome, (b) the effects of DDD pacemakers in patients with sick sinus syndrome and in sex-matched patients with atrioventricular block, and $(c)$ the frequency of cardiac arrhythmias during DDD and VVI modes during Holter monitoring of patients with sick sinus syndrome.

\section{Patients and methods}

\section{PATIENT SELECTION}

We studied 16 patients who had had mode programmable DDD pacemakers implanted at least three months before the study. At the time of the study none of the patients had severe physical disability (for example, arthritis or stroke). Table 1 shows the clinical details. All patients were assessed by prepacing electrophysiological studies including measurement of intervals on $\mathrm{His}$ bundle electrograms, estimation of sinus node recovery times (for atrial pacing rates between 90 and 220 beats/ min), incremental atrial pacing for assessment of Wenckebach cycle length and change of His-ventricular time, assessment of retrograde atrioventricular conduction for ventricular pacing rates of $80-160$ beats/min, and observation of the effects of carotid sinus massage on sinoatrial activity and atrioventricular conduction.

Eight patients had sick sinus syndrome (group 1) and eight had atrioventricular block (group 2). The two groups were age and sex matched. All presented with frequent presyncope and syncope.

There was only one woman in group 1 (mean age 64.1 years (range 41-75)). All had symptomatic sick sinus syndrome, diagnosed electrocardiographically

Table 1 Patient data

\begin{tabular}{|c|c|c|c|c|c|c|c|c|c|}
\hline \multirow[b]{2}{*}{ Case No } & \multirow[b]{2}{*}{ Age/sex } & \multirow[b]{2}{*}{$\begin{array}{l}\text { Other } \\
\text { clinical } \\
\text { diagnosis }\end{array}$} & \multirow[b]{2}{*}{$\begin{array}{l}\text { Prepacing } \\
\text { symptom }\end{array}$} & \multirow[b]{2}{*}{$E C G$ findings } & \multicolumn{3}{|c|}{ Prepacing electrophysiological data } & \multirow[b]{2}{*}{$\begin{array}{l}\text { Months } \\
\text { since } \\
\text { implant }\end{array}$} & \multirow[b]{2}{*}{$\begin{array}{l}\text { Daily drug } \\
\text { treatment }\end{array}$} \\
\hline & & & & & $\begin{array}{l}\text { Sinus } \\
\text { cycle } \\
\text { length } \\
\text { (ms) }\end{array}$ & $\begin{array}{l}C S N R T \\
\text { (ms) }\end{array}$ & $\begin{array}{l}V A \text { conduction } \\
\text { and } \\
\text { interval } \\
\text { (ms) }\end{array}$ & & \\
\hline \multicolumn{10}{|c|}{ Group 1 (SSS): } \\
\hline $\begin{array}{l}1 \\
2 \\
3 \\
4 \\
5 \\
6 \\
7 \\
8 \\
\text { Mean (SD }\end{array}$ & $\begin{array}{l}75 \mathrm{M} \\
74 \mathrm{M} \\
73 \mathrm{M} \\
71 \mathrm{M} \\
68 \mathrm{M} \\
57 \mathrm{M} \\
54 \mathrm{M} \\
41 \mathrm{~F} \\
64 \cdot 1(12 \cdot 2)\end{array}$ & $\begin{array}{l}\text { None } \\
\text { None } \\
\text { None } \\
\text { None } \\
\text { None } \\
\text { HT } \\
\text { None } \\
\text { None }\end{array}$ & $\begin{array}{l}\text { Syncope } \\
\text { Syncope } \\
\text { Syncope } \\
\text { Dizziness } \\
\text { Syncope } \\
\text { Syncope } \\
\text { Syncope } \\
\text { Dizziness }\end{array}$ & $\begin{array}{l}\text { SB } \\
\text { BTS, LBBB } \\
\text { BTS, CRBBB } \\
\text { SA or SAB } \\
\text { BTS } \\
\text { SA or SAB } \\
\text { SA or SAB } \\
\text { SA or SAB }\end{array}$ & $\begin{array}{l}1400 \\
1150 \\
1020 \\
1330 \\
950 \\
1880 \\
1030 \\
990 \\
1219(313)\end{array}$ & $\begin{array}{r}2260 \\
650 \\
570 \\
5400 \\
430 \\
2720 \\
290 \\
870 \\
1649(1760)\end{array}$ & $\begin{array}{l}240 \\
250 \\
200 \\
- \\
190 \\
220 \\
240 \\
250 \\
227(24)\end{array}$ & $\begin{array}{r}48 \\
39 \\
21 \\
5 \\
14 \\
10 \\
14 \\
7 \\
20(16)\end{array}$ & $\begin{array}{l}- \\
- \\
- \\
\bar{N} \text { Nifedipine }(40 \mathrm{mg}) \\
-\end{array}$ \\
\hline \multicolumn{10}{|c|}{ Group 2 (AVB): } \\
\hline $\begin{array}{r}9 \\
10\end{array}$ & $\begin{array}{l}75 \mathrm{M} \\
72 \mathrm{M}\end{array}$ & $\begin{array}{l}\mathrm{AP} \\
\mathrm{OMI}\end{array}$ & $\begin{array}{l}\text { Dizziness } \\
\text { Syncope }\end{array}$ & $\begin{array}{l}\text { CHB } \\
\text { CHB }\end{array}$ & $\begin{array}{l}620 \\
590\end{array}$ & $\begin{array}{l}370 \\
430\end{array}$ & - & $\begin{array}{l}36 \\
20\end{array}$ & $\begin{array}{l}\text { Nifedipine }(20 \mathrm{mg}) \\
\text { Nifedipine }(30 \mathrm{mg}) \\
\text { Metoprolol }(100 \mathrm{mg})\end{array}$ \\
\hline $\begin{array}{l}11 \\
12 \\
13 \\
14 \\
15 \\
16 \\
\text { Mean (SI) }\end{array}$ & $\begin{array}{l}72 M \\
69 M \\
67 M \\
62 M \\
55 M \\
35 F \\
63 \cdot 3(13 \cdot 1)\end{array}$ & $\begin{array}{l}\text { None } \\
\text { None } \\
\text { None } \\
\text { OMI } \\
\text { AP } \\
\text { None }\end{array}$ & $\begin{array}{l}\text { Syncope } \\
\text { Syncope } \\
\text { Dizziness } \\
\text { Syncope } \\
\text { Syncope } \\
\text { Dyspnoea }\end{array}$ & $\begin{array}{l}\text { CHB } \\
\text { CHB } \\
\text { CHB } \\
\text { CHB } \\
2: 1 \text { AVB } \\
\text { CHB }\end{array}$ & $\begin{array}{l}710 \\
830 \\
600 \\
750 \\
740 \\
560 \\
675(96)\end{array}$ & $\begin{array}{l}400 \\
520 \\
430 \\
450 \\
330 \\
310 \\
405(68)\end{array}$ & $\begin{array}{l}- \\
E \\
- \\
-\end{array}$ & $\begin{array}{l}23 \\
34 \\
28 \\
34 \\
17 \\
20 \\
27(7)\end{array}$ & $\begin{array}{l}- \\
\overline{-} \\
\text { Metoprolol }(100 \mathrm{mg}) \\
-\end{array}$ \\
\hline
\end{tabular}

ECG, electrocardiographic; CSNRT, corrected sinus node recovery time; VA, ventriculoatrial: SSS, sick sinus syndrome; SB, sinus bradycardia BTS, gradycardia-tachycardia syndrome; LBBB, left bundle branch block; CRBBB, complete right bundle branch block; SA, sinus arrest; SAB, sinoatrial block; HT, hypertension; AVB, atrioventricular block; AP, angina pectoris; CHB, complete heart block; OMI, old myocardial infarction. 
by persistent resting sinus bradycardia (rate $<55$ beats $/ \mathrm{min}$ ), sinus arrest, and sinoatrial block by conventional electrocardiography and 24 hour Holter recordings. All had evidence of chronotropic incompetence (maximal rate at maximum exercise $<120$ beats/min). Seven of the eight patients with sick sinus syndrome had retrograde atrioventricular conduction. The aetiology was unknown in all group 1 patients. None had symptoms or signs of heart failure.

There were also seven men and one woman in group 2 (mean age 63.3 years (range $35-75$ )). All had symptomatic persistent $2: 1$ or complete atrioventricular block. No patients in group 2 had retrograde atrioventricular conduction, but four had ischaemic heart disease (two with previous myocardial infarction and two with angina of effort).

Patients had had their pacemaker implanted in DDD mode for a mean of 23 months (group 1, 20 months; group 2, 27 months) before entry into the trial to ensure that they were haemodynamically stable at entry.

\section{TRIAL PROTOCOL}

The trial was designed as a within patient double blind prospective study of symptoms and exercise tolerance between the two pacing modes with sufficient time in each mode to permit adaptation. Patients were investigated as outpatients. All patients were programmed in DDD mode before the trial began. We asked patients to keep diary cards of their symptoms for two consecutive months, and a Holter 24 hour period was recorded (sick sinus syndrome patients only) and a maximal stress test was performed at the end of each study period. During the first

Table 2 Sequence of pacing modes

\begin{tabular}{lll}
\hline Case No & First month & \\
\hline Group 1 (SSS): & & Second month \\
1 & DDD & \\
2 & VVI & VVI \\
3 & VVI & DDD \\
4 & DDD & DDD \\
5 & DDD & VVI \\
6 & DDD & VVI \\
7 & VVI & DDD \\
8 & VVI & DDD \\
& & \\
Group 2(AVB): & VVI & DDD \\
9 & VVI & DDD \\
10 & DDD & VVI† \\
11 & DDD & VVI \\
12 & DDD & VVI \\
13 & DDD & VVI \\
14 & DDD & DVI \\
15 & VVI & DDD \\
16 & & \\
\hline
\end{tabular}

^ 14 days in VVI mode; three days in VVI mode. SSS, sick sinus syndrome; AVB, atrioventricular block.
Mitsuoka, Kenny, Yeung, Chan, Perrins, Sut顿n month the pacemaker mode was randomly progranmed to either the VVI or DDD mode. For the second month the alternative mode was programmed. Table 2 shows the sequence of modes for each patient.

At the end of each study month patients performed a symptom limited maximum exercise stress test an electrically braked bicycle ergometer (Sieme Elema). Before entry to the trial patients also had two exercise stress tests to familiarise themselves with the bicycle ergometer and to eliminate a training effect. Exercise was started for a minimum of three minutess at $35 \mathrm{~W}$ and continued to maximum capacity wien $35 \mathrm{~W}$ increases in workload every three minutes. recorded the total workload achieved (in Wattso. Blood pressure was recorded by conventional metcury sphygmomanometer and heart rate was recoiz ded on a three lead electrocardiograph. Blood preø sure and heart rate were recorded on the bicyche before exercise, at the end of every three minute stage, and every two minutes for 10 minutes aft exercise.

Patients with sick sinus syndrome (group 1) al: had 24 hour Holter monitoring by Oxford Medilog (Oxford Medical Instruments) at the end of eacs month. Bipolar electrocardiographic chest leads were fixed to the chest at the V1 and V6 positions. A electrograms were recorded for 24 hours whife patients were ambulant at home and at work. Patienss kept a diary card throughout the recording periof. The electrocardiographic tape recordings were printed by fibreoptic printer (Oxford Medic $\vec{g}$ l Instruments) at a paper speed $25 \mathrm{~mm} / \mathrm{s}$. The electrocardiographic pattern was sampled over eve first and thirty first minute each hour to measure the mean heart rate, diurnal variation of heart rate, and use of the pacemaker. If atrial arrhythmia was present during the observation minute, the rate was not included in the analysis.

Mean heart rate was defined as the average heagt rate during Holter recording. Diurnal variation of heart rate was assessed by comparing the average heart rate at night (from 1 to $4 \mathrm{am}$ ) with the average heart rate by day (from 1 to $4 \mathrm{pm}$ ). We defined pacemaker use as the percentage of beats recorded while the atrial, atrioventricular sequential, or veR tricular modes were operating. Atrial synchronots pacing (VDD mode of operation) was considered sinus-like activity. We defined maximum heart rate as the fastest sinus rate. If the sinus rate did $\mathrm{rgt}_{\mathrm{t}}$ exceed the pacemaker back up rate, the back up raffe was taken as the maximum heart rate.

We also analysed the incidence and frequency of cardiac arrhythmias. We measured the duration äf paroxysmal atrial fibrillation (fibrillation of mose than 5 consecutive beats) and we used the followis identification criteria to measure extrasystoles (ब) 
configuration differing from the regular QRS or pacemaker induced complexes; $(b)$ wide complexes ( $>0.12 \mathrm{~s}$ ); (c) no preceding $P$ wave; $(d)$ prematurity. Frequency was calculated as the number of extrasystoles per 1000 complexes.

We also assessed pacemaker mediated tachycardia. Pacemaker mediated tachycardia was defined as a tachycardia associated with dual chamber sensing pacemakers, which detect a retrograde $P$ wave and conduct anterogradely through the pacing system to trigger another ventricular stimulus and thus perpetuate the tachycardia.

In the VVI mode the rate was set at 70 beats/min. In DDD mode the back up low rate was 60 beats $/ \mathrm{min}$ and the upper P-synchronous rate was 150 beats/ min, with an $A-V$ interval of $150 \mathrm{~ms}$ and Wenckebach upper rate behaviour. Neither the patient nor the observer of the exercise test were aware of the programmed mode. The observer also performed the statistical analysis while still blind to the pacemaker mode. Pacemaker programming and electrocardiographic monitoring during exercise testing were performed by SLC, who did not perform the subsequent analysis.

The patients kept a daily diary card of symptoms, which had been used in a previous study. ${ }^{16}$ They were asked to record the number of attacks of shortness of breath, chest pain, dizziness, palpitation, and syncope that they experienced each day. At the end of each month the patients were also asked to give a subjective score to the following symptoms by comparing them with the previous month: chest pain, dizziness, shortness of breath, palpitation, and general wellbeing. The scores were 1 , much worse; 2 , a little worse; 3 , no change; 4 , a little improved; 5 , much improved. The program mode used for each month was not known by either the patient or the observer who performed the analysis of the record card data.

\section{STATISTICAL METHODS}

We used Student's paired $t$ test to compare maximal effort tolerance and atrial rate at rest and peak exercise. We compared these three variables and heart rate changes during Holter monitoring in groups 1 and 2 by an unpaired $t$ test. Symptoms that were expressed as number of attacks per week for each month and the monthly symptom scores and the duration of arrhythmias were compared by Wilcoxon's ranked sum test. We compared symptom variables between groups 1 and 2 by Mann-Whitney $U$ test. Results (mean (SD)) with a p value of $<0.05$ were regarded as significant.

\section{Results}

\section{GENERAL}

Two patients (8 and 11) had pronounced symptoms in VVI mode and were unable to complete the trial period. They were reprogrammed to DDD at 14 and

Table 3 Monthly symptom scores for shortness of breath and general wellbeing with total workload achieved in VVI and DDD modes together with atrial rates at rest and maximum atrial rates

\begin{tabular}{|c|c|c|c|c|c|c|c|c|c|c|}
\hline \multirow[b]{2}{*}{ Case No } & \multicolumn{2}{|c|}{ Effort tolerance (W) } & \multicolumn{2}{|c|}{$\begin{array}{l}\text { Atrial rate at } \\
\text { rest (bpm) }\end{array}$} & \multicolumn{2}{|c|}{$\begin{array}{l}\text { Maximum atrial rate } \\
\text { (bpm) }\end{array}$} & \multicolumn{2}{|c|}{$\begin{array}{l}\text { Symptom score } \\
\text { "shortness of breath" }\end{array}$} & \multicolumn{2}{|c|}{$\begin{array}{l}\text { Symptom score } \\
\text { "general wellbeing" }\end{array}$} \\
\hline & $D D D$ & $V V I$ & $D D D$ & $V V I$ & $D D D$ & $V V I$ & $D D D$ & $V V I$ & $D D D$ & $V V I$ \\
\hline $\begin{array}{l}\text { Group } 1 \text { (S } \\
1 \\
2 \\
3 \\
4 \\
5 \\
6 \\
7 \\
8 \\
\text { Mean (SD) }\end{array}$ & $\begin{array}{l}\text { SS): } \\
420 \\
520 \\
750 \\
470 \\
570 \\
1265 \\
1183 \\
268 \\
681(363) \ddagger\end{array}$ & $\begin{array}{l}290 \\
490 \\
685 \\
445 \\
815 \\
1265 \\
1010 \\
273 \\
659(353) \ddagger\end{array}$ & $\begin{array}{l}60 \\
68 \\
62 \\
60 \\
68 \\
60 \\
73 \\
80 \\
66(7) \ddagger\end{array}$ & $\begin{array}{l}70 \\
70 \\
70 \\
61 \\
71 \\
70 \\
70 \\
90 \\
72(8) \ddagger\end{array}$ & $\begin{array}{l}71 \\
105 \\
111 \\
127 \\
130 \\
96 \\
136 \\
136 \\
114(23) \ddagger\end{array}$ & $\begin{array}{l}70 \\
88 \\
115 \\
100 \\
115 \\
93 \\
120 \\
139 \\
105(22) \ddagger\end{array}$ & $\begin{array}{l}3 \\
3 \\
3 \\
3 \\
3 \\
3 \\
5 \\
4 \\
3 \cdot 37(0.74) \ddagger\end{array}$ & $\begin{array}{l}1 \\
3 \\
3 \\
3 \\
1 \\
3 \\
1 \\
1 \\
2 \cdot 0(1 \cdot 06) \ddagger\end{array}$ & $\begin{array}{l}3 \\
3 \\
3 \\
3 \\
3 \\
3 \\
5 \\
3 \\
3 \cdot 25(0 \cdot 7)^{\star}\end{array}$ & $\begin{array}{l}1 \\
2 \\
3 \\
3 \\
2 \\
2 \\
1 \\
2 \\
2 \cdot 0(0.75)^{\star}\end{array}$ \\
\hline $\begin{array}{l}\text { Group } 2 \text { (A } \\
9 \\
10 \\
11 \\
12 \\
13 \\
14 \\
15 \\
16 \\
\text { Mean (SD) }\end{array}$ & $\begin{array}{l}\text { VB): } \\
620 \\
718 \\
470 \\
396 \\
567 \\
420 \\
1010 \\
570 \\
596(198) \dagger\end{array}$ & $\begin{array}{l}462 \\
695 \\
268 \\
338 \\
490 \\
320 \\
880 \\
420 \\
484(207) \dagger\end{array}$ & $\begin{array}{c}78 \\
93 \\
68 \\
78 \\
100 \\
83 \\
88 \\
88 \\
85(10) \ddagger\end{array}$ & $\begin{array}{c}95 \\
88 \\
88 \\
68 \\
96 \\
68 \\
90 \\
107 \\
88(14) \ddagger\end{array}$ & $\begin{array}{l}162 \\
150 \\
136 \\
125 \\
130 \\
120 \\
136 \\
142 \\
138(14) \ddagger\end{array}$ & $\begin{array}{l}162 \\
142 \\
125 \\
109 \\
142 \\
115 \\
130 \\
142 \\
133(17) \ddagger\end{array}$ & $\begin{array}{l}4 \\
3 \\
5 \\
3 \\
3 \\
4 \\
3 \\
3 \\
3.5(0.75)^{\star}\end{array}$ & $\begin{array}{l}2 \\
2 \\
1 \\
2 \\
2 \\
1 \\
3 \\
2 \\
1 \cdot 87(0.64) \star\end{array}$ & $\begin{array}{l}4 \\
2 \\
5 \\
3 \\
3 \\
4 \\
3 \\
4 \\
3.5(0.92)^{\star}\end{array}$ & $\begin{array}{l}2 \\
3 \\
1 \\
2 \\
2 \\
2 \\
3 \\
2 \\
2 \cdot 12(0.64)^{\star}\end{array}$ \\
\hline $\begin{array}{l}\text { Group } 1 \\
v \\
\text { Group } 2\end{array}$ & $\ddagger$ & $\ddagger$ & $\ddagger$ & $\ddagger$ & $\star$ & $\star$ & $\ddagger$ & $\ddagger$ & $\ddagger$ & $t$ \\
\hline
\end{tabular}

${ }^{\star} p<0.05, \dagger p=0.001, \ddagger p=N S$. 


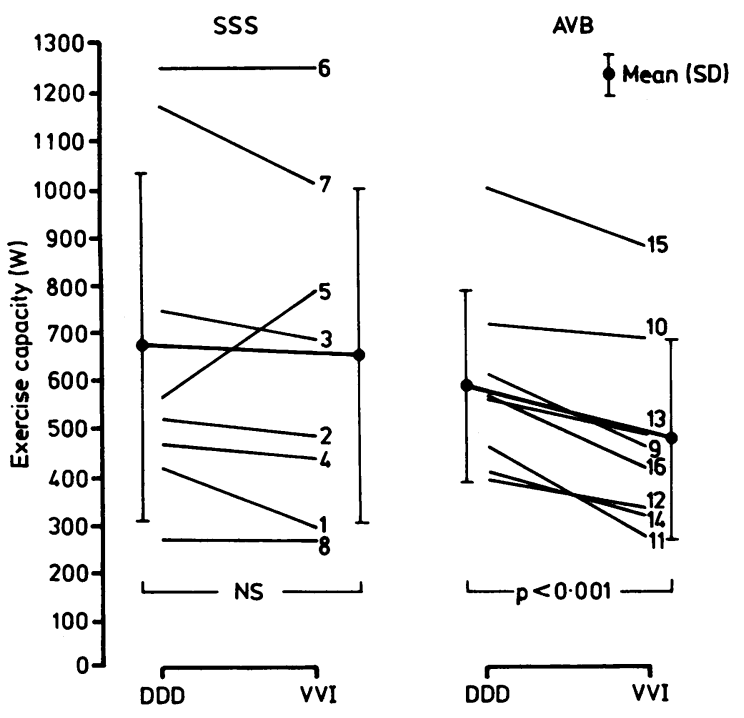

Fig 1 Maximum effort tolerance in DDD and VVI pacing modes in eight patients with sick sinus syndrome and eight patients with atrioventricular block.

three days respectively after exercise tests in VVI mode.

\section{EXERCISE TESTS}

All but two patients stopped the exercise test because of fatigue or shortness of breath. No patient had ventricular tachycardia or hypotension during exercise. In DDD mode, patients 10 and 14 (both with atrioventricular block) stopped exercising because of chest pain. In both cases, patients completed a repeat exercise test within four days and on this occasion both tests were terminated because of fatigue. Data from second tests were used in the analyses.

All patients with sick sinus syndrome, with the exception of patient 1, developed sinus rhythm during exercise in both DDD and VVI modes. Patient 1 showed atrioventricular sequential or ventricular pacing even at peak exercise. In patients with sick sinus syndrome there was no significant difference in maximal effort tolerance between DDD and VVI modes (681 (363) v 659 (353) W) (fig 1 and table 3 ). On the other hand, in patients with atrioventricular block the maximal effort tolerance achieved in DDD mode was $23 \%$ higher than that achieved in the VVI mode (596 (198) v 484 (207) W, $\mathrm{p}=0.001$ ). No patient with atrioventricular block developed intermittent anterograde atrioventricular conduction during stress testing.

The maximal effort tolerance in the DDD mode was higher (but not significantly) in patients with sick sinus syndrome than in those with atrioventricular block (681 (363) v $596(198)$ W).
Mitsuoka, Kenny, Yeung, Chan, Perrins, Sutt

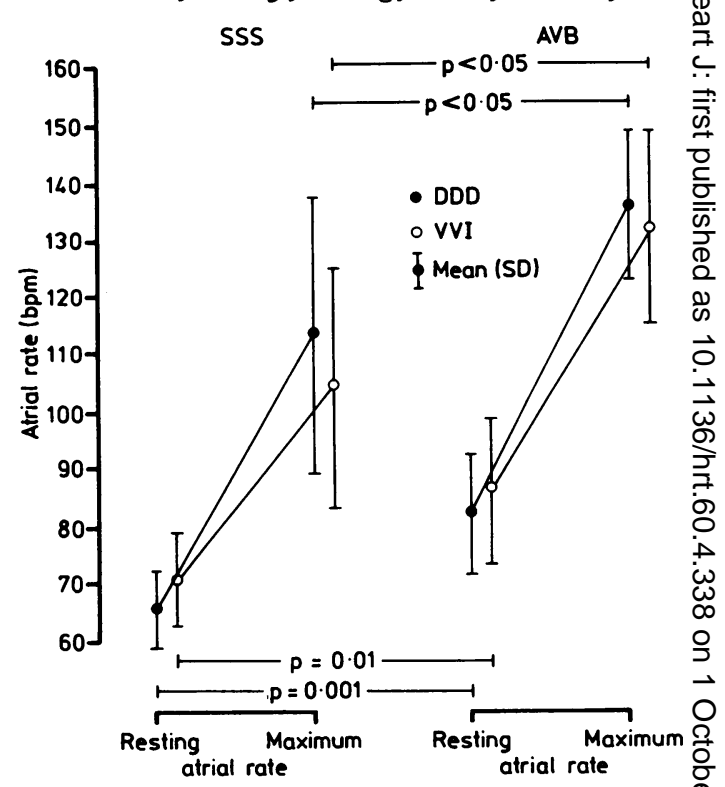

Fig 2 Atrial rate at rest and during peak exercise in DD and VVI modes in eight patients with sick sinus syndrome $\overrightarrow{0}$ and eight patients with atrioventricular block.

There were no significant differences in either the resting or maximum atrial rates achieved during the two pacing modes in the group with atrioventricula block (table 3). On the other hand, maximum atrof rates in the group with sick sinus syndrome were lower in VVI than in DDD mode (105 (22) $v 114(2 \overline{3})$ beats/min), but this difference was not statisticamy significant.

For both the DDD and VVI modes the atrial rates were significantly lower at rest in the sick sin syndrome group than the atrioventricular blogk group (DDD: $66(7) v 85(10)$ beats $/ \mathrm{min}$ ( $\mathrm{p} \bar{\sigma}$ $0.001)$ ); VVI: $72(8) v 88$ (14) beats $/ \mathrm{min}(\mathrm{p}=0.0$ 光)
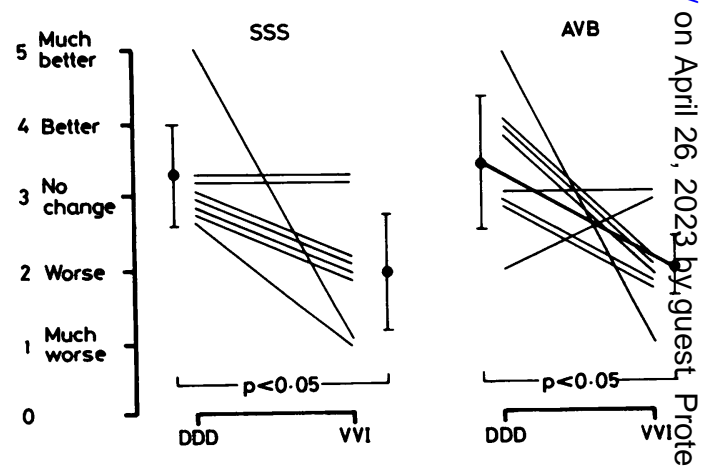

Fig 3 Symptom scores for general wellbeing for $D D D$ an VVI pacing modes in eight patients with sick sinus syndrome and eight with atrioventricular block. 


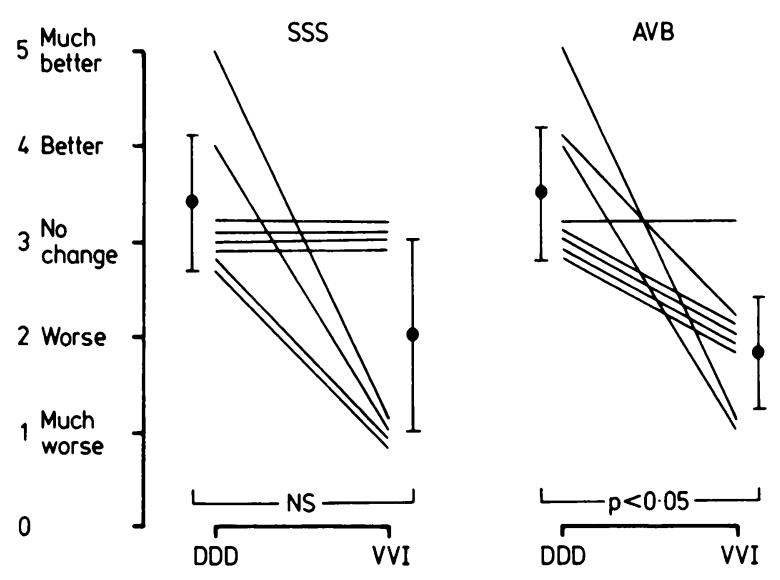

Fig 4 Symptom scores for shortness of breath in DDD and VVI modes in eight patients with sick sinus syndrome and eight patients with atrioventricular block.

(table 3 and fig 2). At peak exercise, the group with sick sinus syndrome again had significantly lower atrial rates than the group with atrioventricular block for both pacing modes-a difference of $20 \%$ in DDD and $23 \%$ in VVI mode (DDD 114 (23) $v 138$ (14) beats/min $(\mathrm{p}<0.05))$; VVI $105(22) v 133$ (17) beats/ $\min (\mathrm{p}<0.05))$.

\section{DIARY CARDS}

The subjective "feeling of general wellbeing" was significantly better in the DDD mode for both groups ( $<<0.05)$ (table 3 and fig 3 ).

The subjective assessment of "shortness of breath" was also better for DDD pacing in atrioven- tricular block $(3.5(0.75)$ v $1.87(0.84)(\mathrm{p}<0.05))$ (table 3 and fig 4 ). In sick sinus syndrome, $50 \%$ of patients were more breathless in the VVI mode.

Table 4 compares the frequency of symptoms during VVI and DDD modes for both patient groups. No patient had syncopal episodes. Palpitation was more frequent during VVI pacing in patients with sick sinus syndrome $(p<0.05)$ for both the weekly attack rate and the monthly symptom score (fig 5). The frequency of palpitation for atrioventricular block patients was not different for the two pacing modes.

No patient with sick sinus syndrome complained of angina-like chest pain. In three of the eight patients with atrioventricular block angina-like chest pains were more frequent during DDD pacing. Patient 10 experienced no anginal episodes in VVI compared with several episodes in DDD mode and therefore preferred the VVI mode.

Fifty per cent of patients with sick sinus syndrome experienced dizziness more often during VVI pacing, but this difference did not reach statistical significance. Patients with conduction tissue disease experienced little dizziness in either pacing mode.

\section{HOLTER MONITORING}

During Holter monitoring in patients with sick sinus syndrome three cardiac arrhythmias were detected: short runs of atrial extrasystoles ( 3 to 5 consecutive beats), paroxysmal atrial fibrillation, and ventricular extrasystoles (both singles and pairs). In DDD mode, only one of the eight patients had paroxysmal atrial fibrillation and another showed 29 episodes of short

Table 4 Weekly attack rates and monthly symptom scores of symptoms for individual patients

\begin{tabular}{|c|c|c|c|c|c|c|c|c|c|c|c|c|}
\hline \multirow{2}{*}{$\begin{array}{l}\text { Case } \\
\text { No }\end{array}$} & \multicolumn{2}{|c|}{$\begin{array}{l}\text { Palpitation } \\
\text { (attacks/wk) }\end{array}$} & \multicolumn{2}{|c|}{$\begin{array}{l}\text { Dizziness } \\
\text { (attacks/wk) }\end{array}$} & \multicolumn{2}{|c|}{$\begin{array}{l}\text { Chest pain } \\
\text { (attacks/wk) }\end{array}$} & \multicolumn{2}{|c|}{$\begin{array}{l}\text { Symptom score } \\
\text { "palpitation" }\end{array}$} & \multicolumn{2}{|c|}{$\begin{array}{l}\text { Symptom score } \\
\text { "dizziness" }\end{array}$} & \multicolumn{2}{|c|}{$\begin{array}{l}\text { Symptom score } \\
\text { "chest pain" }\end{array}$} \\
\hline & $D D D$ & $V V I$ & $D D D$ & $V V I$ & $D D D$ & $V V I$ & $D D D$ & $V V I$ & $D D D$ & $V V I$ & $D D D$ & $V V I$ \\
\hline
\end{tabular}

Group 1 (SSS):

$\begin{array}{clll}\text { (SSS): } & & 0 & 0 \\ 0 & 0 & 0 & 1 \cdot 75 \\ 0 & 0 \cdot 6 & 1 \cdot 25 & 1 \\ 0 & 0 & 0 & 0 \\ 0 & 0 & 0 & 1 \\ 0 & 1 \cdot 75 & 0 & 0 \\ 0 & 2 \cdot 5 & 0 & 0 \cdot 25 \\ 1 & 27 & 0 & 1\end{array}$

$\begin{array}{ll}0 & 0 \\ 0 & 0 \\ 0 & 0 \\ 0 & 0 \\ 1 & 1 \\ 0 & 0 \\ 4 & 6.5 \\ 0.5 & 2.5\end{array}$

$\begin{array}{ll}0 & 3 \\ 0 & 4 \\ 0 & 3 \\ 0 & 3 \\ 1 & 3 \\ 0 & 3 \\ 6 \cdot 5 & 5 \\ 2.5 & 5\end{array}$

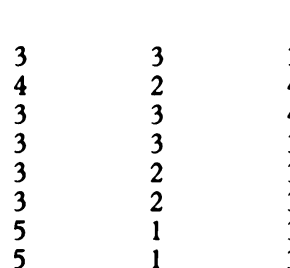

$\begin{array}{llll}3 & 3 & 3 & 3 \\ 4 & 2 & 3 & 3 \\ 4 & 2 & 3 & 3 \\ 3 & 3 & 3 & 3 \\ 3 & 2 & 3 & 3 \\ 3 & 3 & 3 & 3 \\ 3 & 2 & 3 & 2 \\ 3 & 3 & 4 & 2\end{array}$

Mean (SD) $0.12(0.35) \star 5.60(9.68) \star 0.59(1.25)+0.62(0.65)+0.68(1.38)+1.25(2.29)+3.6(0.91) \star 2 \cdot 12(0.83) \star 3.25(0.46)+2.5(0.53) \dagger$

\section{Group 2 (AVB):}

1
1
1
1
1

14

1


runs of atrial extrasystoles.

The frequency and duration of atrial arrhythmias were increased in VVI but the difference between the two modes was not statistically significant (fig 6).

In DDD mode, one of eight patients had frequent ventricular extrasystoles ( $>10 / 1000$ beats). In VVI mode, two further patients had infrequent ventricular extrasystoles ( $<10 / 1000$ beats; table 5$)$.

In the DDD mode two of the eight patients developed runs of pacemaker mediated tachycardia that were brief, self-terminating, and asymptomatic.

In the DDD mode the mean heart rate was 64 beats/min and pacemaker use was $64 \%$. In VVI mode the average heart rate was 74 beats $/ \mathrm{min}$ and pacemaker use was $77 \%$ (NS). In both modes, as expected, the mean heart rate fell and pacemaker use increased at night (table 5).

\section{Discussion}

Because patients with sick sinus syndrome can develop sinus rhythm during exercise and thus were expected to show no difference in maximal effort tolerance between DDD and VVI modes we also studied symptom scores on diary cards and Holter monitoring in addition to exercise testing to assess pacemaker modes. Two exercise tests were performed before entry into the study to counteract the
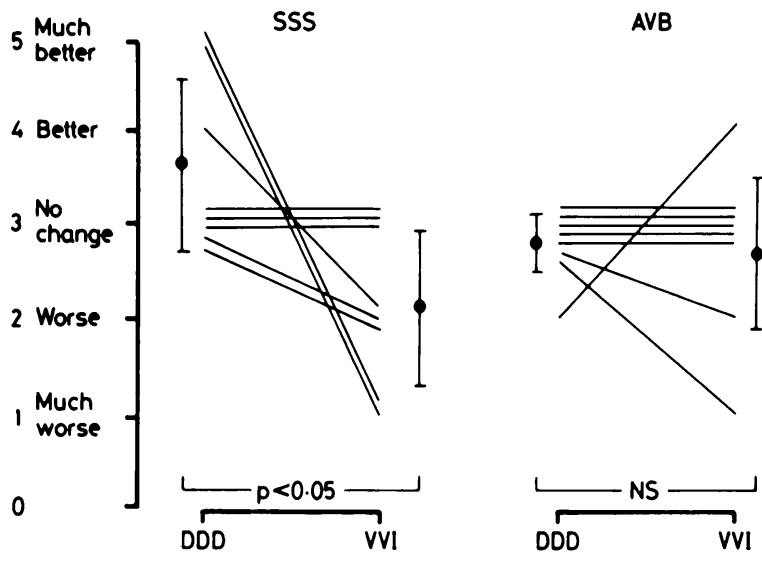

Fig 5 Symptom scores in DDD and VVI modes for palpitation in eight patients with sick sinus syndrome and eight patients with atrioventricular block.

effect of training during subsequent exercise testing. This study was a within patient double blind trial. To eliminate bias both the patient and the investigators were blind to the randomly programmed pacing modes. None the less, some patients did recognise the change to VVI when their heart rate failed to increase with exertion or they developed symptoms. It is impossible for some patients to remain unaware of the pacemaker mode. One of us (SLC) testing was aware of the programmed mode during exercise and

Table 5 Results of Holter monitoring in eight patients with sick sinus syndrome

\begin{tabular}{|c|c|c|c|c|c|c|c|c|}
\hline \multirow{3}{*}{$\begin{array}{l}\text { Case } \\
\text { No }\end{array}$} & \multirow{2}{*}{\multicolumn{2}{|c|}{$\begin{array}{l}\text { Maximum atrial } \\
\text { rate (beats/min) }\end{array}$}} & \multicolumn{6}{|c|}{ Mean heart rate ( $\%$ of pacing rate) } \\
\hline & & & \multicolumn{2}{|l|}{ Night } & \multicolumn{2}{|l|}{ Day } & \multicolumn{2}{|c|}{24 hour } \\
\hline & $D D D$ & $V V I$ & $D D D$ & $V V I$ & $D D D$ & $V V I$ & $D D D$ & $V V I$ \\
\hline \multicolumn{9}{|c|}{ Group 1 (SSS): } \\
\hline 1 & 86 & 118 & $\begin{array}{l}64 \\
(74)\end{array}$ & $\begin{array}{l}72 \\
(89)\end{array}$ & $\begin{array}{l}66 \\
(72)\end{array}$ & $\begin{array}{l}76 \\
(78)\end{array}$ & $\begin{array}{l}65 \\
(76)\end{array}$ & $\begin{array}{l}75 \\
(82)\end{array}$ \\
\hline 2 & 68 & 92 & $\begin{array}{l}60 \\
(96)\end{array}$ & $\begin{array}{l}70 \\
(100)\end{array}$ & $\begin{array}{l}60 \\
(75)\end{array}$ & $\begin{array}{l}71 \\
(93)\end{array}$ & $\begin{array}{l}60 \\
(88)\end{array}$ & $\begin{array}{l}71 \\
(93)\end{array}$ \\
\hline 3 & 93 & 96 & $\begin{array}{l}60 \\
(100)\end{array}$ & $\begin{array}{l}70 \\
(100)\end{array}$ & $\begin{array}{l}69 \\
(5)\end{array}$ & $\begin{array}{l}71 \\
(85)\end{array}$ & $\begin{array}{l}68 \\
(40)\end{array}$ & $\begin{array}{l}73 \\
(69)\end{array}$ \\
\hline 4 & 84 & 80 & $\begin{array}{l}60 \\
(100)\end{array}$ & $\begin{array}{l}70 \\
(95)\end{array}$ & $\begin{array}{l}60 \\
(100)\end{array}$ & $\begin{array}{l}70 \\
(93)\end{array}$ & $\begin{array}{l}60 \\
(100)\end{array}$ & $\begin{array}{l}70 \\
(94)\end{array}$ \\
\hline 5 & 74 & 72 & $-t$ & $\begin{array}{l}70 \\
(100)\end{array}$ & $\begin{array}{l}64 \\
(54)\end{array}$ & $\begin{array}{l}71 \\
(6)\end{array}$ & $\begin{array}{l}61 \\
(69)\end{array}$ & $\begin{array}{l}71 \\
(72)\end{array}$ \\
\hline 6 & 76 & 70 & $\begin{array}{l}60 \\
(100)\end{array}$ & $\begin{array}{l}70 \\
(100)\end{array}$ & $\begin{array}{l}61 \\
(76)\end{array}$ & $\begin{array}{l}70 \\
(100)\end{array}$ & $\begin{array}{l}60 \\
(81)\end{array}$ & $\begin{array}{l}70 \\
(100)\end{array}$ \\
\hline 7 & 102 & 100 & $\begin{array}{l}60 \\
(100)\end{array}$ & $\begin{array}{l}70 \\
(86)\end{array}$ & $\begin{array}{l}75 \\
(0)\end{array}$ & $\begin{array}{l}73 \\
(71)\end{array}$ & $\begin{array}{l}69 \\
(26)\end{array}$ & $\begin{array}{l}71 \\
(80)\end{array}$ \\
\hline 8 & 114 & 152 & $\begin{array}{l}61 \\
(47)\end{array}$ & $\begin{array}{l}71 \\
(56)\end{array}$ & $\begin{array}{l}70 \\
(7)\end{array}$ & $\begin{array}{l}95 \\
(10)\end{array}$ & $\begin{array}{l}66 \\
(31)\end{array}$ & $\begin{array}{l}87 \\
(24)\end{array}$ \\
\hline
\end{tabular}

Cardiac arrhythmias

Total

\begin{tabular}{l}
$\begin{array}{l}\text { Atrial } \\
\text { arrhythmias } \\
\text { (duration }(\text { min })(\text { no/1000) }\end{array}$ \\
\hline$D D D \quad V V I$
\end{tabular}

$\begin{array}{lll}0 & \begin{array}{l}\text { PAF } \\ (76)\end{array} & 0 \\ 0 & \begin{array}{l}\text { PAF } \\ (25)\end{array} & 0 \\ \text { PAF } & \text { PAF } & 0 \\ (110) & (212) & \\ 0 & 0 & 0 \\ 0 & 0 & 0 \\ 0 & 0 & 11 \\ \text { AEs } & 0 & 0 \\ 0 & 0 & 0\end{array}$




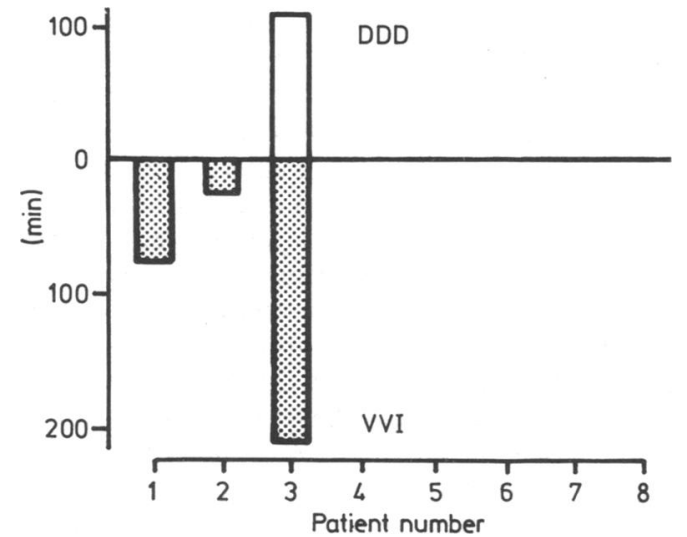

Fig 6 Frequency and duration of atrial fibrillation in DDD and VVI pacing modes for each patient.

monitored the electrocardiogram but took no part in the subsequent data analysis.

\section{DIARY CARDS}

This prospective controlled study showed that DDD pacing is better than VVI in patients with sick sinus syndrome, although there was no difference in effort tolerance between the modes and sinus rhythm developed on each occasion. The beneficial effects of the DDD mode in sick sinus syndrome were evident from the analysis of diary cards. Subjective symptoms of palpitation were significantly $(p<0.05)$ less during DDD pacing; also the patient's overall feeling of wellbeing was significantly $(p<0.05)$ improved. Shortness of breath, however, may be regarded as an exercise related symptom and DDD pacing was not better than VVI pacing in counteracting this symptom in the patients with sick sinus syndrome. In contrast, in patients with atrioventricular block DDD pacing had beneficial effects on both exercise tolerance and shortness of breath. Two patients were unable to tolerate VVI mode and required reprogramming to DDD before completion of the study period. One patient had sick sinus syndrome and the other had atrioventricular block. Both complained of palpitation, shortness of breath, and chest pain (non-anginal) which lasted for seconds to over an hour. These two patients had pacemaker syndrome in VVI.

This study design differed from that of Perrins $e t$ $a l^{16}$ in that there was no randomised run-in period of one month before the trial itself began. All patients in both groups were in DDD before the trial. So after the first month the effects of the DDD mode could be compared with the DDD mode that was previously programmed in nine patients (four in group 1, and five in group 2). As expected, seven reported no change in shortness of breath but two reported an improvement. Both these patients also reported adverse effects when they changed to the VVI mode. Seven patients reported no change in wellbeing after the first month of study and two reported an improvement. Again both of them reported adverse effects in the second month when the VVI mode was operating. Only group 1 had a statistically significant difference between the modes for palpitation. None of the patients with no mode change in the first month reported a change but two of them reported an adverse effect when they changed to VVI in the second month of the trial. For shortness of breath in group 1 DDD was better than VVI in four, with no change in four; and for group 2 DDD was better in seven, with no change in one. For general wellbeing in group 1 DDD was better than VVI in four patients, with no change in four, and in group $2 \mathrm{DDD}$ was preferred by eight with no change in one and VVI was favoured by one who had angina in the DDD mode. For palpitation five group 1 patients preferred DDD and three reported no difference. So only the patient who had angina in DDD preferred the VVI mode. These results indicate that the omission of the one month run-in period did not affect the comparison of the two pacemaker modes.

Pacemaker syndrome normally presents with symptoms of dizziness, syncope, chest pain, and shortness of breath. Several mechanisms have been proposed to explain this syndrome. ${ }^{1317}$ In the presence of retrograde atrioventricular conduction, left atrial pressure rises and cardiac output falls. This results in hypotension, which may be compounded by an inappropriate response in total peripheral resistance. ${ }^{17-19}$ When retrograde atrioventricular conduction is not present, competition between sinus rhythm and ventricular pacing may induce hypotension by causing an acute and transient loss of atrioventricular sychrony.$^{20}$ In this study, most of the patients with sick sinus syndrome who completed the one month study period in VVI mode had symptoms and could be regarded as having a form of pacemaker syndrome (figs 3-5 and tables 3 and 4).

\section{EXERCISE TESTING}

Perrins et $a^{16}$ found that exercise tolerance and symptoms were better in patients with atrioventricular block in VDD (atrial triggered pacing) than in VVI pacing. In the VDD mode, if the atrial rate falls below the programmed low rate, the pacemaker functions as a VVI unit and this makes it unsuitable for pacing patients with sick sinus syndrome. In contrast, as the spontaneous rate decreases in DDD, the pacemaker paces sequentially in the atria and ventricles. In the present study symptomatic assessment of shortness of breath and general wellbeing in patients with atrioventricular block showed similar 
results to the study of Perrins et al. ${ }^{16}$ But they found no difference in the frequency of chest pain between the VDD and VVI modes whereas two of our patients with atrioventricular block had frequent episodes of angina in the DDD mode. In VVI one patient had no angina and the other had an appreciable reduction in anginal episodes. These differences probably reflect differences in patient selection for these two small samples. Kristensson et al reported that a reduction in the upper rate in DDD improves the control of angina in patients with ischaemic heart disease. ${ }^{21}$ Kenny et al confirmed this finding using a double blind technique. ${ }^{22}$

We compared the effect of the DDD mode in sex and age matched subjects with sick sinus syndrome and atrioventricular block. Effort tolerance was better in those with sick sinus syndrome than in those with atrioventricular block, but this difference was not statistically significant. It is possible that four of eight patients with atrioventricular block had ischaemic heart disease which may have limited their exercise tolerance without producing angina. Atrial rates at rest and at peak exercise were significantly lower in patients with sick sinus syndrome for both pacemaker modes. Holden et al also showed that there was no difference in effort tolerance in patients with sick sinus syndrome and normal age matched controls but atrial rates at peak exercise were lower in patients with sick sinus syndrome. ${ }^{23}$ The maintenance of effort tolerance may be the result of haemodynamic adaptation to the relative sinus bradycardia in patients with sick sinus syndrome by augmentation of stroke volume $\mathrm{e}^{20}$ which suggests that in these patients maintenance of atrioventricular synchrony is more valuable haemodynamically than rate responsiveness on exercise.

It can be difficult to diagnose sick sinus syndrome in the presence of atrioventricular block. In the present study we assessed sinus node dysfunction in patients with atrioventricular block by routine electrocardiography, sinus node recovery times, and by Holter recordings. We found no abnormalities.

\section{HOLTER MONITORING}

Holter monitoring showed that the maximal sinus rates achieved on exercise testing are not seen in daily life and that patients spend much of their day with their hearts driven by their pacemakers. This accounts for the better symptomatic benefit shown by the diary cards for dual chamber pacing in terms of general wellbeing, dizziness, and palpitation.

In VVI mode, with a back up rate of 70 beats $/ \mathrm{min}$, patients used their pacemakers $77 \%$ of the time. Adverse symptoms in VVI mode are associated with retrograde atrioventricular conduction. It is of interest to note the degree of pacemaker use within a
24 hour period. Previous work showed that VVI pacing at 50 beats $/ \mathrm{min}$ produces fewer adverse symptoms than rates of 70 beats $/ \mathrm{min}^{24}$ This is directly related to the proportion of time that theo heart is driven by the pacemaker. The DDD mode음 may have been better than the VVI mode in the $\frac{\bar{c}}{5}$ present series because of the lower back up rate for ${ }^{\mathbb{Q}}$ DDD (60 v 70 beats $/ \mathrm{min}$ ). None the less, if retrograde atrioventricular conduction is present, $\rightarrow$ VVI pacing will cause symptoms, whatever the? pacing rate. In addition, if the back up rate is low, $\vec{\omega}$ bradycardia may itself cause symptoms. The shorto runs of pacemaker mediated tachycardia in two patients were asymptomatic and such events cano often be prevented by appropriate programming of the DDD mode.

This study shows that dual chamber pacing may bee better than VVI in the prevention of paroxysmals atrial fibrillation (fig 6, table 5). Sick sinus syndrome is associated with a high incidence of both atrialo fibrillation and systemic embolism, ${ }^{25}$ which are likely음 to be related features. ${ }^{26}$ The aim of atrial stimulation is to prevent bradycardia dependent atrial tachycardias and, by implication, systemic embolism. So faro there is no convincing data to suggest that this has been achieved. Some workers, however, have showno a lower incidence of stroke, heart failure, and chronic atrial fibrillation when AAI pacing rather than VVIO pacing is used ${ }^{27} 28$ but no controlled studies have yetơ been reported.

Ours was a small short term study and other larger $\stackrel{\overrightarrow{0}}{\overrightarrow{0}}$ studies have been short term too, so we cannot be 3 certain that suppression of atrial arrhythmias in sick? sinus syndrome will persist. Atrial stimulation alone. is unlikely to control all atrial arrhythmias, and some patients may also need antiarrhythmic drugs and even anticoagulants. DVI pacing improved symp $-\frac{?}{0}$ toms in sick sinus syndrome more than VVI, ${ }^{29}$ but Furman and Cooper suggest that the increased incidence of atrial arrhythmias in this dual chamber? mode is presumably caused by its lack of an atrialo demand feature. ${ }^{9}$

We found that DDD pacing was better than VVI pacing in patients with sick sinus syndrome, particularly those with retrograde atrioventricular con-o duction. Every sick sinus syndrome patient requiring 0 cardiac stimulation should be considered as a candidate for dual chamber pacing. In this study we dido not compare DDD with atrial demand pacing (AAI) However, a difference between AAI and DDD is unlikely in these patients who showed no evidence of atrioventricular block at pacemaker implantation. If DDD pacing is better than AAI we expect that ie would appear by protecting against the developmens? of atrioventricular block during the lifetime of the pacemaker which, with presently available duab 
chamber units, may be six years or more. There was progession to atrioventricular block causing clinical concern in $8.4 \%$ of patients with no initial atrioventricular conduction defect in a period of 34.2 months in a review of 1395 published cases. ${ }^{8}$

In the future it may prove valuable to use the DDI mode of pacing rather than DDD. In DDI both sets of chambers are paced on demand but atrial triggering of ventricular stimulation does not occur, which prevents the possibility of development of pacemaker mediated tachycardia and this avoids atrial tachycardias triggering a rapid ventricular rate, while DDI still provides all the other attributes of a DDD pacemaker. DDDR pacemakers are becoming available being equipped with an additional sensor to permit dual chamber rate responsive pacing $(R)$ in the event of a lack of response to exercise by the atria. These pacemakers need careful evaluation both in terms of control of symptoms and of atrial arrhythmias and their suppression.

We thank Rosalind Wood for statistical assistance.

\section{References}

1 Kleinert M, Bock M, Wilhemi F. Clinical use of a new transvenous atrial lead. Am J Cardiol 1977;40:237-42.

2 Kruse I, Rydén L, Ydse B. Clinical and electrophysiological characteristics of a transvenous atrial lead. Br Heart J 1979;42:595-602.

3 Klementowicz PT, Furman S. Stability of atrial sensing and pacing after dual chamber pulse generator implantation. J Am Coll Cardiol 1985;6:1338-41.

4 Sutton R. Clinical concerns in dual chamber pacing. In: Zipes DP, ed. Clinical applications of dual chamber pacing. Minneapolis: Medtronic, 1982:86-102.

5 Perrins EJ, Sutton R, Morley C, Chan SL. Natural history of conduction tissue disease in paced patients [Abstract]. Am J Cardiol 1982;49:952.

6 Hayes DL, Furman S. Stability of AV conduction in sick sinus node syndrome patients with implanted atrial pacemakers. Am Heart J 1984;107:644-7.

7 Simonsen E. AV conduction in sick sinus syndrome [Letter]. Am Heart J 1985;109:1407-8.

8 Sutton R, Kenny RA. The natural history of sick sinus syndrome. PACE 1986;9:1110-4.

9 Furman S, Cooper JA. Atrial fibrillation during A-V sequential pacing. PACE 1982;5:133-5.

10 Morley C, Sutton R, Perrins J, Chan SL. The importance of retrograde atrioventricular conduction in physiological cardiac pacing [Abstract]. PACE 1981;4:A-60.

11 Van Mechelen R, Hagemeijer F, De Boer H, Schelling A. Atrioventricular and ventriculo-atrial conduction in patients with symptomatic sinus node dysfunction. $P A C E$ 1983;6:13-21.

12 Ausubel K, Furman S. The pacemaker syndrome. Ann
Intern Med 1985;103:420-9.

13 Kenny RA, Sutton R. Pacemaker syndrome. Br Med J 1986;293:902-3.

14 Amikam S, Riss E. Untoward haemodynamic consequence of permanent ventricular pacing associated with ventriculo-atrial conduction. In: Meere C, ed. Cardiac pacing, state of the art 1979. Proceedings of the $V I t h$ world symposium on cardiac pacing, Montreal, 1979: 15.6

15 Nishimara RA, Gersh BJ, Viletstra RE, Osborn MJ, Ilstrup DM, Holmes DR Jr. Haemodynamic and symptomatic consequences of ventricular pacing. $P A C E$ 1982;5:903-10.

16 Perrins EJ, Morley CA, Chan SL, Sutton R. Randomised controlled trial of physiological and ventricular pacing. Br Heart J 1983;50:112-7.

17 Erlebacher JA, Danner RL, Stelzer PE. Hypotension with ventricular pacing: an atrial vasodepressor reflex in human beings. J Am Coll Cardiol 1984;4:550-5.

18 Johnson AD, Laiken SL, Engler RL. Haemodynamic compromise associated with ventriculoatrial conduction following transvenous pacemaker placements. Am J Med 1978;65:75-9.

19 Alicandri C, Fouad FM, Tarati RC, Castle L, Morant $\mathrm{V}$. Three cases of hypotension and syncope with ventricular pacing: possible role of atrial reflexes. $\mathrm{Am}$ $J$ Cardiol 1978;42:137-42.

20 Furman S. Cardiac pacing and pacemakers VI. Analysis of pacemaker malfunction. Am Heart J 1977;94: 378-86.

21 Kristensson BE, Arnam K, Ryden L. Atrial synchronous ventricular pacing in ischaemic heart disease. Eur Heart $J$ 1983;4:668-73.

22 Kenny RA, Ingram A, Mitsuoka T, Walsh K, Sutton R. Optimum pacing mode for patients with angina pectoris. Br Heart J 1986;56:463-8.

23 Holden W, McAnulty JH. Rahimtoola SH. Characterisation of heart rate response to exercise in the sick sinus syndrome. $\mathrm{Br}$ Heart $\mathrm{J}$ 1978;40:923-30.

24 Rosenquist M, Vallin HO, Edhag KO. Rate hysteresis pacing: how valuable is it? A comparison of the stimulation rates of 70 and 50 beats per minute and rate hysteresis in patients with sinus node disease. PACE 1984;7:332-40.

25 Fairfax AJ, Lambert CD, Leatham A. Systemic embolism in chronic sinoatrial disorder. N Engl J Med 1976;295:190-2.

26 Kannell WB, Abbott RD, Savage DD. McNamara PM. Epidemiologic features of chronic atrial fibrillation. The Framingham Study. N Engl J Med 1982; 306:1018-22.

27 Sasaki S, Takeuchi A, Ohzeki M, et al. Long-term follow-up of paced patients with sick sinus syndrome [Abstract]. PACE 1983;6:A-121.

28 Rosenquist M, Brandt J, Schuller $H$. Atrial versus ventricular pacing in sinus node disease: a treatment comparison study. Am Heart J 1986;111:292-7.

29 Stone JM, Bhakta RD, Lutgen J. Dual-chamber sequential pacing management of sinus node dysfunction: advantages over single-chamber pacing. $\mathrm{Am}$ Heart J 1982;104:1319-27. 